\title{
A sala de aula de Paulo Freire - um estudo sobre o Ciclo do Conhecimento
}

Nilson Antônio Guzzo Junior (Professor de Filosofia e Sociologia no Colégio Barroco Lopes e no Centro Educacional Bruno Ostman, situados em Macaé)

https://orcid.org/0000-0003-0881-8248

Stephen Bigler (Professor de Matemática e Física nos Colégio Estadual Jornalista Tim Lopes, na Escola Chile e na Escola Teresa Cristina, todos no Rio de Janeiro)

https://orcid.org/0000-0001-6365-320X

\section{Resumo}

A aquisição do aprendizado denota uma forma de produzir conhecimento cuja ênfase está no conhecimento tácito e nas habilidades cognitivas. Na sala de aula, no entanto, este axioma não é considerado e, muitas vezes, o programa não é concebido a partir das histórias dos alunos, não é considerada esta forma aprender. É fundamental que os conteúdos da matéria sejam ministrados considerando as pedagogias próprias dos alunos. Cada aluno tem uma história, e aprender, a partir de uma gênese de produção do conhecimento que evidencia o conhecimento tácito de cada um, permite alargar as fronteiras cognitivas e alavancar progressivamente o conhecimento geral. O Ciclo Gnosiológico de Paulo Freire mostra esta forma de aprender.

Palavras-chave: Conhecimento. Informação. Ciclo do conhecimento. Interações sociais.

Data de submissão: 24/09/2018

Data de aprovação: 08/10/2018

\begin{abstract}
The acquisition of learning denotes a way of producing knowledge whose emphasis is on tacit knowledge and cognitive abilities. In the classroom however, this axiom is not considered and often the program is not designed from the students' stories, it is not considered this way to learn. It is essential that the contents of the subject be given considering the pedagogies of the students. Each student has a history and learns from a genesis of knowledge production that evidences the tacit knowledge of each one, allows to widen the cognitive borders and progressively leverage the general knowledge. The Paulo Freire cycle of knowledge shows this way of learning.
\end{abstract}

Keywords: Knowledge. Information. Knowledge cycle. Social interactions.

\section{Introdução}

Pretende-se mostrar, neste artigo, que na sala de aula, na maioria das vezes, em decorrência de um programa estabelecido, o aprendizado dá-se no campo do conhecimento explícito, e, neste escopo, não se fala em ampliar as habilidades cognitivas, não se propõe o consenso de valores das pedagogias 
próprias dos alunos, todo o esforço é para formar o aluno no conhecimento programático das técnicas e tecnologias.

Entende-se aqui como habilidades cognitivas a atenção, percepção, assimilação, entendimento, raciocínio, criatividade, alternativas de solução de problemas, representação, memória, consciência crítica. Percebe-se que tais habilidades são desenvolvidas em grupo; talvez seja esta a missão mais difícil da escola e do professor, provocar o consenso e alargamento destas habilidades.

Atualmente, em função de um novo paradigma (apresentado na ilustração 1), há um apelo ao fazer sozinho, ao aprenda a fazer sozinho; esta ênfase no técnico e no tecnológico reflete na sala de aula o novo paradigma, trazido pela globalização, desemprego e crise ecológica. A sala de aula tornou-se refém desse novo paradigma, como mostrado na figura abaixo.

Talela 1: $\mathrm{O}$ antigo paradigma versus o novo paradigma

\begin{tabular}{|l|l|}
\hline $\begin{array}{l}\text { PECULIARIDADES DO ANTIGO } \\
\text { PARADIGMA }\end{array}$ & $\begin{array}{l}\text { PECULIARIDADES DO NOVO } \\
\text { PARADIGMA }\end{array}$ \\
\hline Destino coletivo & Destino Pessoal \\
\hline Empreendimentos conjuntos & Empreendedor de si mesmo \\
\hline Individualismo & Novo individualismo \\
\hline Nós & Eu \\
\hline Performance da equipe & Culto à performance individual \\
\hline Aprendizado Colaborativo & Autodidata \\
\hline $\begin{array}{l}\text { O mito da caverna - necessidade } \\
\text { de enxergar o mundo real }\end{array}$ & $\begin{array}{l}\text { Desejo de que tudo esteja conec- } \\
\text { tado - lógica dos eventos ainda } \\
\text { por revelarem-se }\end{array}$ \\
\hline Estabilidade profissional & Instabilidade profissional \\
\hline Busca por segurança & Desejo de liberdade \\
\hline Fiel à empresa & Fiel à carreira \\
\hline
\end{tabular}

Fonte: sistematizado do livro de Bendassoli (2007)

O novo paradigma entrou nas salas de aula, derrubou as fronteiras das interações sociais e trouxe o novo individualismo, e nós, como professores, teremos que resistir a esta perda da individualidade. Pesce (2010) está certa quando afirma que:

(...) os seres humanos são historicamente datados (...) se constituem mutuamente, por meio da linguagem e dos históricos processos de interação social, nos quais se engendram negociações de sentido.

A sala de aula hoje com metodologias, programas e lacunas cognitivas é uma sala datada que corresponde ao desejo de passar para o aluno a responsabilidade de ser empresário de sua própria vida, construindo sua história pessoal (EHRENBERG, apud BENDASSOLI, 2007). Aqui cabe uma reflexão: o aluno é responsável, sim, pelo seu próprio aprendizado, mas a metodologia de ensino deve ser participativa, em consonância com o nosso destino coletivo.

É fundamental que a matéria transmitida pelo professor se enriqueça com os esquemas de interpretação do mundo, de aceitação ou rejeição do outro, trazidos pelos alunos. Podemos trazer de volta o indivíduo social? Podemos abrir consenso aos cognitivos e superar o imenso vazio interacional que 
nos trouxe o novo paradigma?

Paulo Freire chama esta relação dialógica entre docente e discente de dodiscência (2009, p. 28). Ele afirma que o ato de "ensinar exige pesquisa" (2009, p.29), não só a realizada pelo discente, mas a pesquisa que o professor realiza em cada palavra falada ou escrita pelo aluno. Quando este passo não é realizado pelo professor em ambientes virtuais ou em sala de aula, cada aluno isolado em si mesmo, torna-se ele mesmo, sem troca, sem ganhar novos valores oriundos do reconhecimento e da relação com o outro.

(...) Nos tornamos nós mesmos através dos outros" (1984, p. 56) (...) a construção social do indivíduo é uma história de relações com outros, através da linguagem, e de transformações do funcionamento psicológico constituídas pelas interações face-a-face e por relações sociais mais amplas. (VYGOTISKY, 1984, apud GOES, 2000, p. 121).

Juciene Moura de Nascimento e Edenia Maria Ribeiro do Amaral (2012) destacam que:

(...) a abordagem Vygotskiana enfatiza um sujeito do conhecimento não apenas passivo, moldado por regulações externas, e nem tampouco apenas ativo, moldado por regulações internas, mas, um sujeito interativo e dinâmico em suas escolhas e atitudes, cuja história de vida vai sendo construída à medida que, socialmente, integra-se a outras histórias de vida, incorporando valores, hábitos e experiências, assim como a própria linguagem daqueles com quem interage. (...) Tomando por base a perspectiva Vygotskiana, consideramos que as interações em sala de aula são fundamentais para a formação do aluno, pois, tendem a promover uma troca significativa de conhecimentos e experiências que influenciam os processos de maturação cognitiva de cada um. As parcerias aluno-aluno e professor-aluno permitem a ampliação do universo social educacional do aluno, facilitando a aprendizagem dos conceitos, e, portanto, as interações sociais constituem parte importante do processo de ensino-aprendizagem.

\section{Metodologia}

A metodologia utilizada neste artigo é qualitativa e pressupôs uma pesquisa bibliográfica, na qual compareceram com seus conceitos, Paulo Freire, Fernando Bendassoli. Buscou-se traçar as diferenças entre o ciclo de conhecimento padrão, cuja ênfase é no conhecimento explícito, e o conhecimento gnosiológico de Paulo Freire, cuja ênfase é nas habilidades cognitivas e no conhecimento tácito.

\section{O ciclo gnosiológico de Paulo Freire}

Paulo Freire (1997) estudou o ciclo do conhecimento, que chamou de ciclo gnosiológico, e afirmava que:

(...) se observarmos o ciclo do conhecimento, podemos perceber dois momentos, e não mais que dois, dois momentos que se relacionam dialeticamente. $\mathrm{O}$ primeiro momento do ciclo é o momento da produção de um conhecimento novo, de algo novo. O outro momento é aquele em que o conhecimento produzido é conhecido ou percebido. 
Paulo Freire afirmava que, ao refletir sobre a sua própria experiência de aprendizagem, o aluno cognoscente desenvolve as qualidades requeridas na conscientização do conhecimento: reflexão crítica, percepção, curiosidade, questionamento exigente, inquietação, incerteza. Ele dizia que, quando isolamos a produção do conhecimento da reflexão sobre o que foi produzido, quando o isolamos da conscientização do que se aprendeu, o ato do conhecimento se transforma em uma mera transferência de conhecimento (FREIRE, 1997, p.18).

A troca de experiências entre os membros do grupo no decurso da realização de trabalhos conjuntos, durante a definição de alternativas de solução para problemas técnicos, é o momento fundador do ato de conhecimento, da gnose, que compreende ouvir o outro, apreender novos saberes e descortinar a possibilidade de conhecer e descortinar outras experiências.

A questão de partilhar práticas oriundas da esfera relacional durante a solução conjunta de problemas não é apenas abertura de espaços para a participação mais ampla dos alunos. Trata-se de uma heterogênese na construção da informação, nas relações de aprendizagem conjunta, uma reflexão sobre a gênese e consequências históricas das habilidades cognitivas e do conhecimento, tendo em mente a instrução geral, diante do mistério insondável do que somos.

A Pedagogia da Autonomia (2009, 32), de Paulo Freire, destaca que "ensinar exige estética e ética", ou seja, o ensino/aprendizado tem como implicação desenvolver a percepção do aluno (estética) e conduzir para uma maior integração do eu e do outro (Ética). Os exercícios no ambiente tecnológico terão que ser pensados pelo professor para o intercâmbio de percepções, promovendo, de forma progressiva, a interculturalidade dos alunos.

Não importa se à distância ou presencialmente, o professor terá que dar conta de que "ensinar exige pesquisa" $(2009,29)$ e "exige respeito aos saberes dos educandos" $(2009$, p.30); será preciso estimular que os alunos compartilhem valores, e caberá ao professor ter a percepção do conhecimento tácito às respostas dadas pelos alunos.

Para produzir os efeitos do aprendizado, a informação tem que ser construída respeitando-se as suas propriedades, ou seja, na construção da informação há um conhecimento explícito e um conhecimento tácito de um conhecimento existente, que se combinam com textos fornecidos pelo docente.

Cada aluno tem a possibilidade de recursivamente e progressivamente torna-se "um outro e o mesmo", na mimese axiomática da educação. É por esse motivo que a educação promove a construção de novas identidades.

O conhecimento que o aluno traz para a sala de aula sempre vem carregado de valores. A partir desta mistura entre tácito e explícito, é que os indivíduos, junto com outros, podem transformar ou reforçar seu ponto de vista e desenvolver uma visão crítica da vida. $\mathrm{O}$ educador tem que estar consciente de seu papel de transformador de mentes. Ele não pode perder este momento raro de ouvir, ver, ler os valores que ali são representados e trocados entre os alunos.

Ao ensinar e cobrar a matéria do programa, cabe ao professor ter a percepção das habilidades de cada aluno, ao mesmo tempo em que estimula a percepção dos valores pelos alunos, das crenças que eles trazem para a sala de aula. Para o bem fazer educacional, o professor deve levar em conta estes dois pontos fundamentais:

- "ensinar exige o reconhecimento e a assunção da identidade cultural” (2009 p. 41) - aqui é preciso que o professor estimule a interculturalidade em sala de aula através dos trabalhos conjuntos, instando 
o aluno a assumir sua identidade cultural e reconhecendo e respeitando o outro;

- "ensinar exige risco, aceitação do novo, e rejeição de qualquer forma de discriminação" (2009, p. 35) - nesta etapa, o professor precisa assumir o risco de sua escolha de ser professor, aceitar o novo, aceitar o outro e rejeitar qualquer forma de discriminação. $\mathrm{O}$ conjunto tácito de práticas oriundas da esfera relacional não é uma mercadoria à venda, mas uma realidade constitutiva da mente humana, que absorve e internaliza as experiências, um algo interno, sem o qual deixa de existir, uma realidade antropológica fundamental, de cujo exercício e compartilhamento depende a própria existência do ser humano, sua qualidade de ser e de se situar no mundo. Em interação, em sala de aula, o aluno aprende e se renova com o que aprendeu, entrando em campo progressivamente e permanentemente com um novo conhecimento, que, num ato gnosiológico, é posto novamente em relação.

Deseja-se que o professor assuma a responsabilidade em relação à sua prática. Ele é único e, portanto, precisa intervir efetivamente no processo de ensino e aprendizagem e ser capaz de estabelecer objetivos e prioridades e de definir as reais necessidades dos sujeitos.

Entende-se que a descontextualização e o isolamento do ensino (...) em relação aos reais problemas vivenciados pelos estudantes são grandes desafios a serem superados por práticas realmente comprometidas. É preciso ultrapassar o panorama da educação científica que apresenta como majoritária a orientação propedêutica do ensino, em detrimento de outros âmbitos formativos importantes, tais como atitudes, valores, relações entre Ciência, Tecnologia e Sociedade (CATARINO; LIMA; QUEIROZ, 2015).

\section{A reflexão crítica}

O professor tem um importante papel na Pedagogia da Autonomia, que é instar o aluno as práticas educativas de reflexão sobre aquilo que faz, ou seja, "ensinar, exige reflexão crítica sobre a prática". Aqui reside uma chave muito importante da Pedagogia da Autonomia (2009, p. 38), que é ampliar o consenso da habilidade cognitiva da reflexão crítica. No Ciclo Padrão do Conhecimento, esta habilidade não é compartilhada e ampliada, pois o foco do ciclo padrão são os exercícios programáticos, e o professor cobra do grupo o compartilhamento de soluções exclusivamente técnicas.

No Ciclo de Conhecimento Padrão, os dois momentos de produção e percepção do conhecimento produzido são anômicos, vazios de valores tácitos e de sentido cognitivo. No Ciclo Gnosiológico Freireano, o indivíduo é outro e, ao mesmo tempo, é ele mesmo; de forma recursiva, aprende e junto constrói um novo quadro de referências cognitivas, ampliando o conhecimento tácito e o explícito, com os quais conceitua e socializa o que sabe.

O aluno, no silêncio do seu espírito crítico, produz o novo conhecimento e o percebe em si mesmo, pois ele agora é portador de um novo conhecimento explícito e tácito produzido em sala de aula.

\section{Considerações finais}

O Ciclo Gnosiológico do Conhecimento Freireano (1997) pressupõe os alunos com experiências semelhantes ou distintas, necessidades de informação análogas ou diferentes em interação das maneiras de pensar, agir e sentir, numa pedagogia promovida pelo professor, que estimula a partilha de valores culturais, aplicados no crescimento do grupo, em estreita interação uns com os outros, durante a rea- 
lização dos trabalhos do programa da disciplina.

O que imprime confiança na fabulação escolar para uma aula nova é que o conjunto de experiências vividas, dia após dia, ultrapassa o individual e abarca o coletivo, porque todos vivem em sociedade, e se pressupõe cada pessoa desdobrando-se e se desenvolvendo em todas as suas habilidades. No microcosmo de uma sala de aula, há um sujeito social e um sujeito individual. É preciso usar a favor da educação este fenômeno, que está na base do desenvolvimento do ser humano.

O final temporário de um ciclo de aprendizado é a incorporação gradual de valores, de crenças, de novos pontos de vista. O sujeito que aprende compartilha progressivamente novas práticas que compartilhou. Esta é a responsabilidade da informação em seu caminho: operar sobre o conhecimento, produzindo novas práticas em seus receptores, preparando-os para uma vida comunitária carregada de sentido.

Segundo Moraes (2012), o acesso às novas tecnologias de informação e comunicação dinamiza a troca de ideias entre indivíduos de uma comunidade e destes com a sociedade. Tanto o indivíduo, quanto a comunidade e a sociedade ganham na construção conjunta da informação e desta forma evidencia-se o ciclo gnosiológico ${ }^{1}$, que faz emergir em novos patamares, o conhecimento, que se reproduz colado às experiências da comunidade, à sua trajetória, alargando as cortinas da morada, reforçando os valores que dizem respeito à postura pessoal crítica frente ao mundo, tais como ética, motivação, criatividade, novas formas de ver o mundo e elevação da autoestima e da heteroestima.

O Ciclo Gnosiológico de Freire (1997, p.18) demonstra que o confinamento de ideias é prejudicial à reflexão crítica, ao questionamento, indispensáveis ao sujeito cognoscente, denotando que o processo de desenvolvimento gnosiológico foi pobre e não propiciou o desenvolvimento da cognição, ou seja, o professor não atravessou as fronteiras da sala de aula e não lançou pontes com a vida dos alunos, e o aluno não abstraiu do aprendizado um novo sentido e direção para o que aprendeu.

(...) o processo de se perceber educador é complexo, cheio de tensões. Nosso sujeito se apresenta, então, um docente que vive em meio a essas tensões: a tensão da contra- hegemonia - acreditar em uma educação que vai além da simples transmissão de conteúdo (currículo tradicional/mecanicista), mas que permeia diversas dimensões do aluno como Ser Humano, como um Ser dialógico que se constitui coletivamente; a tensão de sua identidade híbrida (hibridismo como forma de conhecimento) - um professor que vive na fronteira em sala de aula (CATARINO; LIMA; QUEIROZ, 2015)

A educação é sempre uma teoria do Conhecimento posta em prática. (FREIRE, 1997). E, neste contexto, no campo do conhecimento, o professor deverá desenvolver metodologias próprias para promover a interculturalidade entre os alunos em suas turmas e agenciar o intercâmbio das pedagogias e conhecimento tácito dos alunos e suas habilidades cognitivas. Ao aceitar este desafio freireano, o professor será protagonista junto com seus alunos da protoforma de uma mudança cultural de grande envergadura. 


\section{Referências}

BAUMAN, Zigmunt. Modernidade líquida. Rio de Janeiro: Zahar, 2015

BAUMAN, Zigmunt. Sociedade individualizada: vidas contadas e histórias vividas. Rio de Janeiro: Zahar, 2008

BENDASSOLI, Pedro Fernando. Identidade e trabalho em tempos sombrios. São Paulo: Ideias e Letras, 2007

CATARINO, G. F. C.; LIMA, M C A.; QUEIROZG.R.P. A prática docente e o dialogismo bakhtiniano: O ensino como um ato responsável. Ciência \& Educação. Bauru, v.21 n. 4, out./dez. 2015. Disponível em: <http://www.scielo.br/scielo.php?script=sci_arttext\&pid=s151673132015000400004\&ln$\mathrm{g}=$ pt\&tlng=pt.> Acesso em 23 jan. 2018.

FREIRE, Paulo. Pedagogia da autonomia. São Paulo : Paz e Terra. 2009. 148 p.

FREIRE, Paulo. Medo e ousadia cotidiano do professor. 7. ed. São Paulo : Paz e Terra. 1997. 223 p.

GÓES, Maria Cecília Rafael. A formação do indivíduo nas relações sociais: Contribuições teóricas de Lev Vygotsky e Pierre Janet In: Educação \& Sociedade, ano XXI, n 71, Julho/00. Disponível em: http://www.scielo.br/pdf/es/v21n71/a05v2171.pdf. Acesso em 23 de janeiro de 2018.

MORAES et al. O ciclo padrão do conhecimento e o ciclo invertido na aquisição de informação e no "letramento" em comunidades: uma nova heterogênese da informação, liderança e poder. In: PINHEIRO, Lena Vania Ribeiro (Org.); OLIVEIRA, Eloísa da Conceição Príncipe de (Org.). Múltiplas facetas da comunicação e divulgação científicas : transformações em cinco séculos. Brasília: IBICT, 2012. p. 350 - 365.

MORAES, R; VALIM. R. O Adão isolado e a heterogênese do Adão cooperativo. Revista Carioca de Ciência, Tecnologia e Educação. Rio de janeiro: Unicarioca, v.2, n.1, p. 121-136, 2017.

NASCIMENTO J. M.; AMARAL e. M. R. O papel das interações sociais e de atividades propostas para o ensino-aprendizagem de conceitos químicos. Ciência \& Educação, Bauru, v.18, n..3, 2012. Disponível em: < http://www.scielo.br/scielo.php?script=sci_arttext\&pi$\mathrm{d}=\mathrm{s} 1516-73132012000300006 \&$ lng=pt\&tlng=pt. $>$. Acesso em: 23 de janeiro de 2018.

PESCE, L. A formação online de educadores sob enfoque dialógico. Disponível em: <file://le:/ interculturalidade/racionalidade\%20instrumental\%20à\%20racionalidade\%20comunicativa. pdf. 2010>. Acesso em:23 de jan. 2018.

VYGOTSKY, L.S. A formação social da mente. São Paulo: Martins Fontes, 1998. 